\title{
Insertion Device Upgrade Plans at the NSLS
}

\author{
T. Tanabe, A. Blednykh, D. Harder, M. Lehecka, G. Rakowsky, \\ and J. Skaritka \\ NSLS, Brookhaven National Laboratory, Upton, NY
}

May, 2005

\section{National Synchrotron Light Source}

Brookhaven National Laboratory

Managed by

Brookhaven Science Associates

Upton, NY 11973

Under Contract with the United States Department of Energy

Contract Number DE-AC02-98CH10886 


\section{DISCLAIMER}

This report was prepared as an account of work sponsored by an agency of the United States Government. Neither the United States Government nor any agency thereof, nor any of their employees, nor any of their contractors, subcontractors or their employees, makes any warranty, express or implied, or assumes any legal liability or responsibility for the accuracy, completeness, or any third party's use or the results of such use of any information, apparatus, product, or process disclosed, or represents that its use would not infringe privately owned rights. Reference herein to any specific commercial product, process, or service by trade name, trademark, manufacturer, or otherwise, does not necessary constitute or imply its endorsement, recommendation, or favoring by the United States Government or any agency thereof or its contractors or subcontractors. The views and opinions of authors expresses herein do not necessarily state to reflect those of the United States Government or any agency thereof. 


\title{
INSERTION DEVICE UPGRADE PLANS AT THE NSLS
}

\author{
T. Tanabe, A. Blednykh, D. Harder, M. Lehecka, G. Rakowsky and J. Skaritka \\ BNL, Upton, NY 11973, U.S.A.
}

\begin{abstract}
This paper describes plans to upgrade insertion devices (IDs) at the National Synchrotron Light Source (NSLS), Brookhaven National Laboratory, U.S.A. The aging wiggler (W120) at X25 is being replaced by a $1 \mathrm{~m}$ long in-vacuum mini-gap undulator (MGU-X25) optimized for a dedicated macromolecular crystallography program. A new, 1/3 m long, undulator (MGU or SCU-X9), will be installed between a pair of RF cavities at X9, and will serve a new beamline dedicated for small angle x-ray scattering (SAXS). Both IDs will have provision for cryocooling the $\mathrm{NdFeB}$ hybrid arrays to $150 \mathrm{~K}$ to raise the field and K-value and to obtain better spectral coverage. Design issues of the devices and other considerations, especially magnetic measurement at low temperature, will be discussed.
\end{abstract}

\section{INTRODUCTION}

Originally designed as a second-generation synchrotron light source, the NSLS VUV and X-ray Rings inherently lack enough straight sections to accommodate many insertion devices. 2 IDs on the VUV ring have not been updated for some time due to a lack of demand for new usage. However, major efforts have been made to upgrade the existing IDs and to create extra space to accommodate undulators in the X-ray Ring. There are currently 7 devices in place and three of those have recently been updated. Two of them (X13, X29) are minigap undulators (MGUs) and another one (X13 in tandem with MGU) is an elliptically polarized undulator. A new RF cavity system will be installed in X9 straight section during the winter shutdown in FY05, and it will create a small space for another ID. Table 1 shows the list of existing IDs and their parameters in the X-ray ring.

Table 1: NSLS-Xray ring ID Parameters.

\begin{tabular}{|l||l|l|l|l|}
\hline ID-\# & 1 & $13 / 29$ & 17 & $21 / 25$ \\
\hline \hline $\mathrm{B}[\mathrm{T}]$ & $0.31-$ & $0.95-$ & 5poles@5.2 & 1.1 \\
& 0.03 & 0.1 & 2poles@2.6 & \\
\hline $\mathrm{N}$ & 33.5 & 27 & & 12.5 \\
\hline$\lambda \mathrm{u}[\mathrm{mm}]$ & 8 & 1.25 & 17.4 & 12 \\
\hline $\mathrm{Ec}[\mathrm{KeV}]$ & - & - & $22.2 @ 5.2 \mathrm{~T}$ & 4.57 \\
\hline $\mathrm{E} 1[\mathrm{KeV}]$ & $0.19-$ & $3.7-$ & $10-100$ & $4-30$ \\
\hline $\mathrm{K}$ & $2.3-0.2$ & $1.1-0.5$ & 80.9 & 12.3 \\
\hline Gap[mm] & $33-98$ & $3.3-$ & 32 & $24-120$ \\
\hline
\end{tabular}

\section{X25 CRYO-READY INVACUUM UNDULATOR}

The most recent ID (MGU-X25) upgrade at NSLS is a new cryo-ready in-vacuum undulator on X25 beamline, which replaces a 15-year-old wiggler. It will provide a high-brightness, tunable $\mathrm{x}$-ray source over the photon range of 1.9-20 keV, with continuous coverage in overlapping bands, utilizing the fundamental, $2^{\text {nd }}, 3^{\text {rd }}, 5^{\text {th }}$, $7^{\text {th }}$ and $9^{\text {th }}$ harmonics. Unlike newer, low-emittance, "third-generation" light sources, there is a significant and usable $2^{\text {nd }}$ harmonic on-axis due to the rather large emittance of the $2.8 \mathrm{GeV}$ electron beam. The tuning range of the $2^{\text {nd }}$ harmonic fills the gap between the top of the 2:1 tuning range of the fundamental $(1.9-3.8 \mathrm{keV})$ and the bottom of the $3^{\text {rd }}$ harmonic's range $(5.7 \mathrm{keV})$. MGU-X25 will deliver to the Protein Crystallography program on the X25 beamline between 30 times and 2 times brighter $\mathrm{x}$ ray beams over its entire tuning range, compared with the old X25 Wiggler.

\section{ID Parameters and its Design Principle}

A Cryo-Permanent Magnet Undulator (CPMU) design was recently presented by SPring-8 group [1]. The idea is simply to take advantage of the increased remanent field of $\mathrm{NdFeB}$ magnets at lower temperature, peaking around 150K. However, real implementation imposes a few major challenges as follows:

1) The structure should maintain the accurate gap and straightness over the range of $250 \mathrm{~K}$ in the case of an in-vacuum undulator which requires baking. Since higher harmonics up to the $9^{\text {th }}$ are expected to be used, the phase error requirement is tighter than for other MGUs.

2) Maintaining a uniform temperature over the entire magnet arrays. The effect of temperature non-uniformity is equivalent to gap error.

3) The magnitude of the increase of the remanent field for individual magnets may vary, which could increase phase/multipole errors if not shimmed at the actual operating temperature.

4) Difficulty of in-situ measurement and shimming. Table 2: MGU-X25 Parameters. Bold letters are for 150K.

\begin{tabular}{|l||c|c|}
\hline \multicolumn{1}{|l||}{ Period $[\mathrm{mm}]$} & \multicolumn{2}{c|}{18} \\
\hline Gap $[\mathrm{mm}]$ & \multicolumn{2}{c|}{$5.6-12$} \\
\hline \# of Periods & 1.3 & $\mathbf{1 . 4 5}$ \\
\hline $\mathrm{Br}(\mathrm{T})$ & $0.9-0.3$ & $\mathbf{1 . 0 0 - 0 . 3}$ \\
\hline $\mathrm{B}_{\text {peak }}(\mathrm{T})$ & $1.5-0.5$ & $\mathbf{1 . 6 8 - 0 . 5}$ \\
\hline $\mathrm{K}$ & $1.9-3.6$ & $\mathbf{1 . 7 - 3 . 6}$ \\
\hline E1 $(\mathrm{keV})$ & $5.8-9.6$ & $\mathbf{5 . 1 - 8 . 5}$ \\
\hline E3 $(\mathrm{keV})$ & $9.6-13.4$ & $\mathbf{8 . 5 - 1 1 . 9}$ \\
\hline E5 $(\mathrm{keV})$ &
\end{tabular}

Unlike the original SP8 proposal in which magnet material with highest remanent field was used, despite its low intrinsic coercivity, we have decided to use a new

Notice: This manuscript has been authored by Brookhaven Science Associates, LLC under Contract No. DE-AC02-98CH1-886 with the U.S.

Department of Energy. The United States Government retains, and the publisher, by accepting the article for publication, acknowledges, a

world-wide license to publish or reproduce the published form of this manuscript, or allow others to do so, for the United Government purposes. 
high remanence, high temperature grade of $\mathrm{NdFeB}$ (NEOMAX 42AH with $\mathrm{Br}=1.3 \mathrm{~T}$ and $\mathrm{Hcj}=24 \mathrm{kOe}$ ).that can be used as a conventional in-vacuum undulator at room temperature (in case of failure of the cooling system), and that can be baked to 100C.

A hybrid structure utilizing vanadium permendur was selected as in other MGUs here at NSLS in order to maximize the available field. Since it is relatively short device, it is important to maximize the number of poles contributing to the brilliance. Therefore, our termination scheme is optimized to minimize phase error beginning with the third pole from the end.

The maximum allowed phase error is determined to be 2 degree rms to preserve spectral quality of higher harmonics. With a gap of $5.6 \mathrm{~mm}$, the exerted force on the magnet arrays exceeds $600 \mathrm{~kg}$, and even with 4 supports, the maximum allowed peak-to-valley deflection is $6.5 \mu \mathrm{m}$ with a given error budget of 0.75 degree rms. Having the same amount of error budget, only $3.2 \mu \mathrm{m}$ is tolerated in terms of gap tapering. Since this ID does not have uniform temperature over the entire device, the conventional method of using external linear encoders cannot ensure this level of accuracy at the gap. Hence, we have decided to use direct gap measurement using a LEDbased system (Keyence LS-7030) which has a measurement accuracy of $\pm 2 \mu \mathrm{m}$ and repeatability of $\pm 0.15 \mu \mathrm{m}$. Figure 1 delineates the CAD design of the section. The Keyence units and the encoders are guarded against radiation with lead shielding.

To minimize temperature gradients in the magnet support beams, gas cooling passages are milled into the platen and the beam is welded by the friction stir weld method.

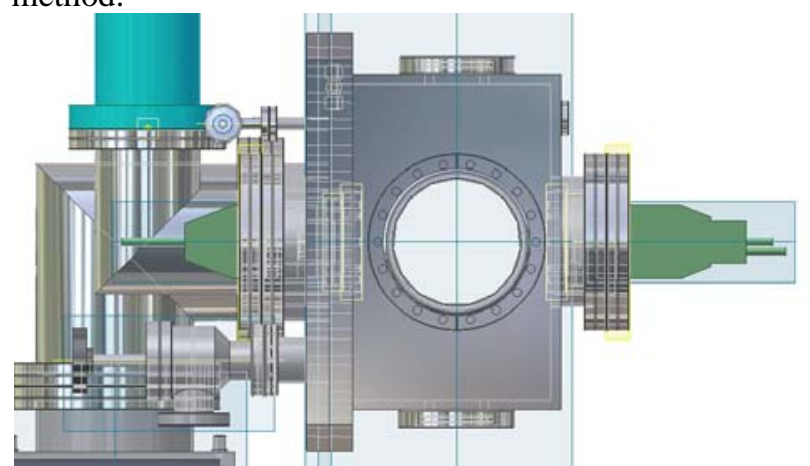

Figure 1: Keyence optical sensing units (green pieces) attached on the sides of the vacuum chamber windows in order to directly measure undulator gap.

\section{Cold Temperature Magnetic Measurement}

It is known that the remanent field of $\mathrm{NdFeB}$ magnets has a negative temperature coefficient. For example, NEOMAX-42AH has $-0.10 \% /{ }^{\circ} \mathrm{C} @ 20^{\circ} \mathrm{C}$. Using linear extrapolation a $2 \%$ field increase is expected at $0^{\circ} \mathrm{C}$. In reality the increase tapers off gradually as the temperature goes lower and it peaks around $150^{\circ} \mathrm{K}$, with an expected increase of at least $10 \%$. Bizen, et al. found that radiation resistance also increases in lower temperature due to the increase of intrinsic coercivity [2].
However, it is not clear how these increases behave statistically with a collection of magnets in IDs. The field optimized at room temperature may not retain the degree of errors at lower temperature.

\section{Measurement Results at -71.5C}

Various field measurements were done using a Hall probe developed for the Vertical Test Facility (VTF) which was designed to survey superconducting undulator testing [3]. The probe has an array of 6 Hall sensors (Lakeshore, HGT-2100-10) which were calibrated against an NMR probe both at room temperature and at $77^{\circ} \mathrm{K}$ in liquid nitrogen. Manufacturer's specification of the output voltage dependence on temperature $\left(-0.6 \% /{ }^{\circ} \mathrm{K}\right.$ between $-55{ }^{\circ} \mathrm{C}$ and $20{ }^{\circ} \mathrm{C}$ ) was used to interpolate the calibration to dry ice temperature. (A calibration in dry ice against the NMR is in preparation.)

Spare "Prototype Small-Gap Undulator" arrays, which consist of NdFeB in a 6 block/period pure-PM structure, and a 10-pole PM-hybrid MGU prototype were used for comparison. The magnets were packed in cry ice for the cold tests. Magnet temperatures were monitored with platinum resistance temperature devices (RTDs) at multiple locations. Several different measurements were done as are shown below:

1) PSGU (gap $=6 \mathrm{~mm}$ ) at room temperature and at $-71.5^{\circ} \mathrm{C}$. 2) $\mathrm{MGU}(\mathrm{gap}=4.75 \mathrm{~mm})$ at room temperature and at $-66^{\circ} \mathrm{C}$.

Table 1 shows the parameters of those IDs. Figure 2 represents the second integrals of PSGU filed maps for the two temperatures. Some differences in trajectory errors and $1^{\text {st }}$ integrals are seen.

Table 1: ID magnet array parameters tested.

\begin{tabular}{|l|l|l|}
\hline & PSGU & MGU \\
\hline \hline Magnet Type & PPM & PM-Hybrid \\
\hline Length (m) & 0.32 & 0.15 \\
\hline Period (mm) & 16 & 13.5 \\
\hline No. periods & 18.5 & 3.5 \\
\hline Magnet gap (mm) & 6.0 & 4.75 \\
\hline $\mathrm{K}_{\max }$ & 0.94 & 1.1 \\
\hline Peak field (T) & 0.623 & 0.95 \\
\hline No.blocks/period & 6 & 2 (hybrid) \\
\hline Pole material & $\mathrm{n} / \mathrm{a}$ & Permendur \\
\hline Magnet material & NdFeB & NdFeB \\
\hline
\end{tabular}

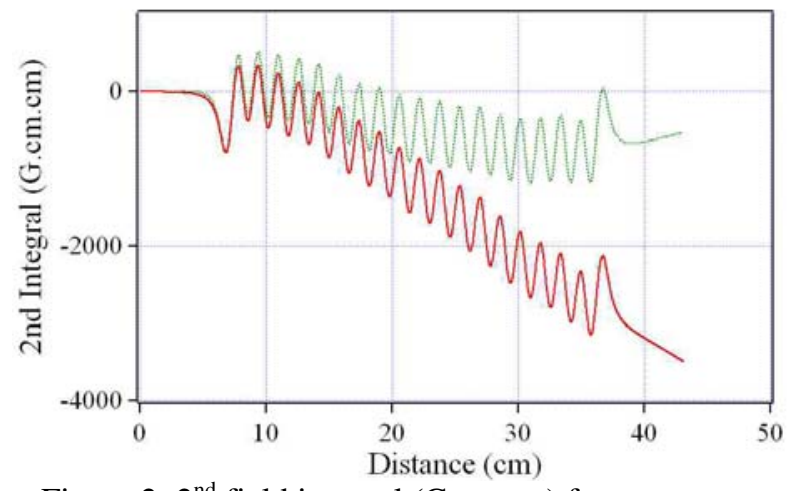

Figure 2: $2^{\text {nd }}$ field integral (G.cm.cm) for warm scan (Red solid line) and cold scan (green dotted line) 
Figure 3 (a) represents the first 1000 field values in descending order for both the warm and cold measurement of the PSGU magnets, and Fig. 3 (b) is the first 200 values for the MGU. The peak in the highest field region is artificially created using the second peak from the beginning and the third peak from the end. The green line is the ratio of the two curves after probe gain compensation. The average value of the field increase for the PSGU and the MGU are found to be $9.29 \%$ and $8.16 \%$, respectively. Both values are in good agreement with the thermal coefficient of $-0.1 \% /{ }^{\circ} \mathrm{K}$, which is the manufacturer's specification at room temperature. Note that even a 6 degree phase error (three times the normal specification) will reduce the $3^{\text {rd }}$ harmonic only by $10 \%$. Therefore, even without cold shimming, cooling will be an effective to close the spectral gaps in lower harmonics.
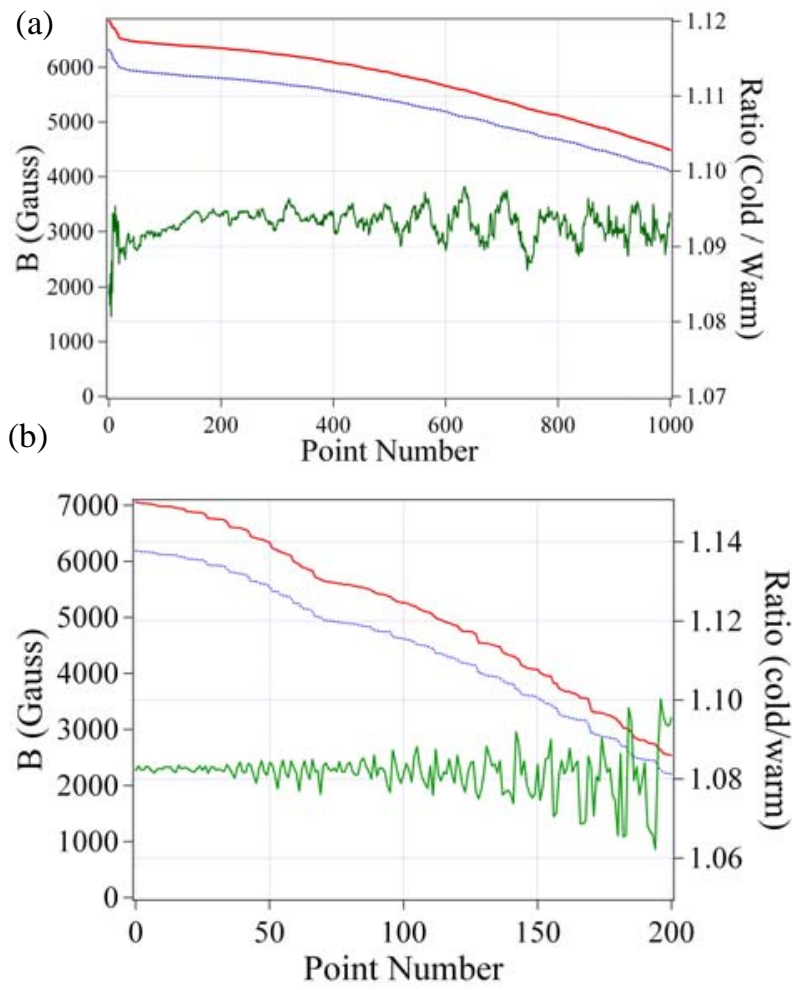

Figure 3: The first 1000 field values for the PSGU magnets (a) at $-71.5^{\circ} \mathrm{C}$ and 200 values for the MGU prototype (b) at $-66^{\circ} \mathrm{C}$ in descending order. The red curve represents the average values of 4 cold scans and the blue dotted line is the average of 4 warm scans. The green line represents the ratio of cold values to warm values after temperature compensation of $5.5 \%$ and $5.0 \%$, respectively.

\section{IMPEDANCE ISSUES}

It is known that the transition from the regular vacuum chamber to the small gap in the MGU would create a wake fields which increases the ring impedance. Power dissipated in the region results in heating. Figure 4 shows the imaginary part of impedance for the MGU device at $3.3 \mathrm{~mm}$ gap. The corresponding value for a $5 \mathrm{~mm}$ gap is $140 \mathrm{k} \Omega / \mathrm{m}$. A value of $300 \mathrm{k} \Omega / \mathrm{m}$ can be tolerated in the current NSLS ring, however, a considerable reduction of impedance is required for device which will be installed in NSLS-II. So far most people's attention has been focused on the taper angle of the transition only. However, simulation results show that the vacuum chamber in the transverse direction can act as a resonator if both sides of the magnetic array gap are open [4]. A new design taking this effect into account is underway.

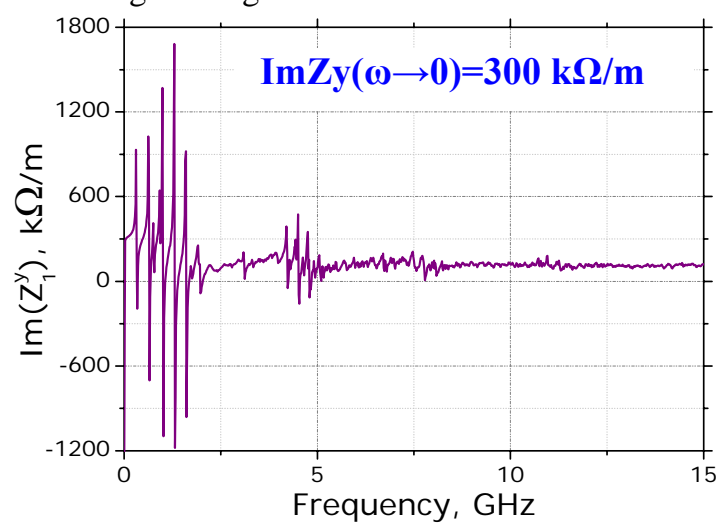

Figure 4: Imaginary part of the impedance for the MGU at a gap of $3.3 \mathrm{~mm}$.

\section{NEW X-9 UNDULATOR}

The next new ID for the X-ray ring will be at X9. The undulator dimension will be almost identical to MGUX13 and MGU-X29. Currently two candidates are being considered. The first is CPMU which utilizes design features in MGU-X25. The second is a superconducting undulator (SCU) which will use the state of the art superconductor technology such as artificial pinning centers (APC) NbTi wire, YBCO tape or $\mathrm{MgB}_{2}$ wire. A conceptual design study has been carried out and its cutaway view is delineated in Fig. 4.

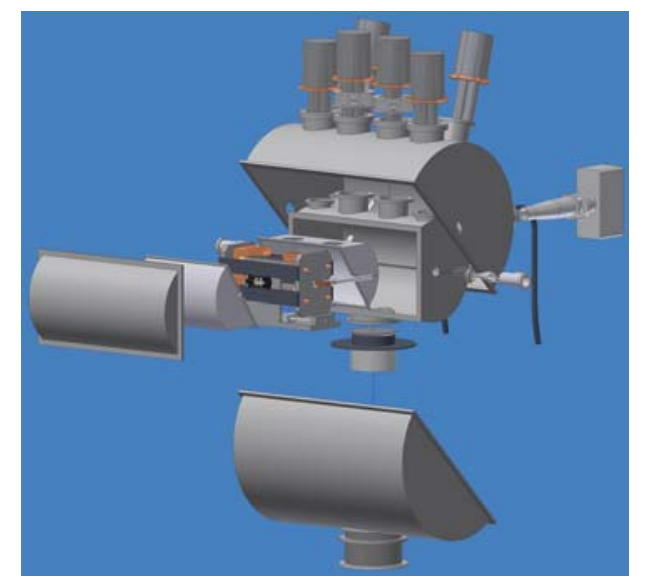

Figure 4: A cut-away view of X-9 SCU design.

\section{REFERENCES}

[1] T. Hara, et. al., Phys. Rev. ST-AB, Vol. 7, 050702 (2004).

[2] T. Bizen, et. al., Proceedings of EPAC04, Lucerne, Switzerland, 2092 (2004).

[3] D. Harder, et. al., These proceedings.

[4] A. Blednykh, et. al., These proceedings. 
